\title{
Trans-vaccenic acid inhibits proliferation and induces apoptosis of human nasopharyngeal carcinoma cells via a mitochondrial-mediated apoptosis pathway
}

Jian Song ${ }^{1,2}$, Yujie Wang ${ }^{1,2}$, Xiaoqin Fan ${ }^{1,2}$, Hanwei Wu ${ }^{1,2}$, Jinghong Han ${ }^{3}$, Ming Yang ${ }^{4}$, Lu Lu ${ }^{1}$ and Guohui Nie , 2* $^{*}$

\begin{abstract}
Background: Intake of trans fatty acids (TFAs) from partially hydrogenated vegetable oil is associated with a variety of adverse outcomes, but little is known about the health effects of ruminant trans fats. Trans-vaccenic acid (TVA) is a naturally occurring TFA found in the fat of ruminants and in human dairy products. The present study was conducted to investigate the anticancer activity and underlying mechanisms of TVA on human nasopharyngeal carcinoma (NPC) 5-8F and CNE-2 cells.

Methods: A CCK8 assay was used to determine the effect of TVA and the Mcl-1 inhibitor 563845 on the proliferation of NPC cells. Apoptosis was measured using flow cytometry. Western blotting was used to detect the protein expression levels of factors associated with Bcl-2-family protein signaling and Akt signaling.

Results: TVA significantly inhibited cell proliferation in a dose-dependent manner. Mechanistic investigation demonstrated that TVA significantly decreased p-Akt levels and Bad phosphorylation on Ser-136 and Ser-112. More importantly, we discovered that the Mcl-1 inhibitor $\mathbf{6 3 8 4 5}$ synergistically sensitized NPC cells to apoptosis induction by TVA.

Conclusion: TVA can inhibit NPC cell growth and induced apoptosis through the inhibition of Bad/Akt phosphorylation. The combined use of TVA and Mcl-1 inhibitors offers a potential advantage for nasopharyngeal cancer treatment.
\end{abstract}

Keywords: Trans-vaccenic acid, Apoptosis, Nasopharyngeal carcinoma, Akt, Bad, Mcl-1

\section{Introduction}

Trans fatty acids (TFAs) is a general term for unsaturated fatty acids with at least one double bond in the trans configuration [1]. TFAs within the human diet are mainly derived from industrial partial hydrogenation of vegetable oils and from natural sources, such as ruminant animal products. Evidence suggests that TFAs from

\footnotetext{
* Correspondence: nghui@21cn.com

'Department of Otolaryngology, Shenzhen Second People's Hospital, The First Affiliated Hospital of Shenzhen University, Shenzhen 518035, People's Republic of China

${ }^{2}$ Institute of Translational Medicine, Shenzhen Second People's Hospital, The First Affiliated Hospital of Shenzhen University, Shenzhen 518035, People's Republic of China

Full list of author information is available at the end of the article
}

different sources cause various biological effects on human health that may be beneficial or unfavorable $[2,3]$.

The impact of TFAs on the cardiovascular system has been extensively studied, and many epidemiological investigations and experiments have shown that TFAs from partially hydrogenated oils have adverse effects on the cardiovascular system [4]. TFAs formed via industrial hydrogenation could significantly accelerate the development of atherosclerosis by increasing the ratio of low-density lipoprotein (LDL) to high-density lipoprotein (HDL) [5]. In addition, many other studies have shown that these types of TFAs also have adverse effects on blood lipids [6], inflammation [7], oxidative stress [8], endothelial health [9], body weight [10], insulin sensitivity [11] and cancer [12]. However, emerging evidence

(C) The Author(s). 2019 Open Access This article is distributed under the terms of the Creative Commons Attribution 4.0 International License (http://creativecommons.org/licenses/by/4.0/), which permits unrestricted use, distribution, and 
indicates that trans fats derived from milk or ruminant body fats are beneficial for reducing the incidence of cardiovascular disease, cancer and obesity [13].

Trans-vaccenic acid (TVA) is ubiquitous in ruminantderived fats and human dairy products such as milk and butter. It is worth noting that TVA is also the predominant TFA in human milk. Supplementation with milk lipids that contain TVA triggers a pronounced cytotoxic effect on HT29 cell due to conversion to c9,t11-conjugated linoleic acid (CLA) [14]. Suppression of tumor cell growth by TVA treatment of the MCF7 and SW480 cell lines can be attributed to the induction of apoptosis though increased DNA fragmentation and reduced cytosolic glutathione levels [15]. Preclinical studies have shown that the use of various types of fatty acids alone or combined with other anticancer drugs has promising therapeutic application prospects [16].

Nasopharyngeal carcinoma (NPC), the most common cancer originating in the nasopharynx, has a high incidence in Southern China and Southeast Asia [17]. Radiotherapy is currently the preferred method of treatment for early-stage NPC because most NPCs are poorly differentiated cancers with high sensitivity to radiation and because the primary and neck lymphatic drainage areas are easily included in the radiotherapy field [18]. Clinical treatment of recurrent or metastatic NPC is more difficult than primary NPC treatment. The routine treatment for these groups of patients is platinum-based chemotherapy, which confers a median progression-free survival time of 7 months [19]. Therefore, it is urgent to identify a more effective treatment option for patients with recurrent or metastatic NPC.

In the present study, we demonstrate that TVA effectively induces NPC apoptosis in 5-8F and CNE-2 cells. Mechanism studies indicate that TVA significantly inhibits Akt/Bad phosphorylation. More importantly, we found that TVA treatment also led to the upregulation of Mcl-1 as a novel mechanism involved in TVA resistance, which could be overcome by treatment with the Mcl-1 inhibitor S63845. These results suggest that the combination of TVA and Mcl-1 inhibitors is a promising approach for NPC treatment strategies.

\section{Materials and methods}

\section{Cell culture and treatments}

The human NPC cell lines 5-8F and CNE-2 were a generous gift from Prof. Chao-Nan Qian at the State Key Laboratory of Oncology in South China and the Collaborative Innovation Center for Cancer Medicine, Sun Yat-Sen University Cancer Center. All NPC cell lines were maintained in RPMI-1640 medium (SH30809.01, HyClone) supplemented with 10\% FBS (10099-141, Gibco) and 1\% penicillin-streptomycin (15070-063, Gibco) at $37^{\circ} \mathrm{C}$ with $5 \% \mathrm{CO}_{2}$.
For treatments, the cells were grown in 6-well plates to $60-70 \%$ confluence and were then treated with different concentrations of TFAs (EA, LA, and TVA; Nu-Chek Prep) $(0,25,50,100,200 \mu \mathrm{M})$ for $24 \mathrm{~h}$. Equal concentrations of DMSO were used as the controls.

\section{Cell viability assay}

The effect of TFAs on the viability of NPC cells was measured by CCK 8 assay. 5-8F and CNE-2 cells were plated $\left(1.5 \times 10^{4}\right.$ cells $)$ in 96 -well culture plates and incubated in serum-containing medium for $24 \mathrm{~h}$. The medium was then replaced with serum-free media containing different concentrations of TFA and/or S63845 (HY-100741, MedChem Express) for 24 h. After incubation, cell proliferation was analyzed with a CCK8 assay kit following the manufacturer's instructions (CK04, Dojindo Laboratories), and the absorbance at $450 \mathrm{~nm}$ was measured using a microplate reader (BioTek).

\section{Annexin $\mathrm{V}$ and propidium iodide $(\mathrm{PI})$ staining}

The effects of the TFAs on apoptosis were determined by dual staining with annexin V-FITC and PI using an apoptosis detection kit from BD Bioscience. After treatment with the indicated TFA concentrations for $24 \mathrm{~h}$, the cells were harvested and washed with PBS. The cells were then incubated with $5 \mu \mathrm{L}$ of annexin V-FITC and PI for $15 \mathrm{~min}$. The fluorescence of the cells was analyzed by flow cytometry (Beckman Coulter).

\section{Western blot assay}

After treatment, lysates from the cultured cells were prepared with RIPA buffer, and the protein concentrations were determined with a BCA Protein Assay Reagent Kit (23227, Thermo Scientific). The lysates were separated by electrophoresis on a $12 \%$ SDS-polyacrylamide gel and then transferred to PVDF Western Blotting Membranes (IPVH00010, Millipore). The membranes were blocked with $5 \%$ milk and incubated at $4{ }^{\circ} \mathrm{C}$ with primary antibodies against Bad (9292, Cell Signaling Technology, 1:1000), phosphor-Bad (Ser-112) (5284, Cell Signaling Technology, 1:1000), phosphor-Bad (Ser-136) (4366, Cell Signaling Technology, 1:1000), Mcl-1 (94,296, Cell Signaling Technology, 1:1000), Bcl-xL (2764, Cell Signaling Technology, 1:1000), Bcl-2 (12789-1-AP, Proteintech, 1:1000), pan-Akt (4685, Cell Signaling Technology, 1:1000), p-Akt (Ser-473) (4060, Cell Signaling Technology, 1:1000), p-Akt (Thr-308) (13,038, Cell Signaling Technology, 1:1000), and $\beta$-tubulin (10068-1-AP, Proteintech, 1:5000). After overnight incubation with the primary antibodies, the membranes were incubated with secondary anti-mouse (115-035-003, Jackson, 1:5000) or anti-rabbit (111-035-003, Jackson, 1:5000) antibodies. Then, the signals were detected with an Amersham Imager 600 . 


\section{Calculation of the combination index}

Whether the synergistic inhibitory effect between TVA and $\mathrm{S} 63845$ can be determined by the combination index (CI) using the Chou-Talalay equation [20]. 5-8F and CNE-2cells were treated with various concentrations of TVA and S63845 separately or in combination. The total inhibitory effect was assessed by CCK 8 assay as described above. The CI value was determined as follow:

$$
C I=\frac{D A, x}{I C x, A}+\frac{D B, x}{I C x, B}
$$

A, B represents two different agent, ICX, A and ICX, $B$ are the concentration when the two agent are used alone to achieve a growth inhibition rate of $\mathrm{X} \%$, and $\mathrm{DA}, \mathrm{x}$ and $\mathrm{DB}, \mathrm{x}$ are the concentration of two agent combined to achieve a growth inhibition rate of $\mathrm{X} \%$. $\mathrm{CI}<1$ indicate synergism, $\mathrm{CI}=1$ indicates additive effects, and $\mathrm{CI}>1$ indicates antagonism.

\section{Statistical analysis}

Statistical analysis was performed using the standard Student $\mathrm{t}$ test for pair comparisons and ANOVA analysis for multiple factors. The statistical values of $* P<0.05$, ${ }^{* *} P<0.01$ and $* * P<0.001$ were considered statistically significant. Values of mean determinants are presented as \pm s.e.m.

\section{Results}

\section{TVA inhibits NPC cell viability in a dose-dependent} manner

To determine the effect of TVA on NPC cells viability, we treated two human NPC cell line subtypes, 5-8F and CNE-2 (highly metastatic strain) with TFAs using a range of doses. After $24 \mathrm{~h}$ of treatment, cell viability was evaluated using a CCK8 assay. We found that all 3 TFAs exerted inhibitory effects on 5-8F and CNE-2 cell viability in a dose-dependent manner (Fig. 1a). The number of cells was significantly lower in the low-dose TVA $(50 \mu \mathrm{M})$ group than in the control group, whereas $100 \mu \mathrm{M}$ LA and $200 \mu \mathrm{M}$ EA supplementation suppressed NPC cells viability to a significant degree. The growth inhibitory ratios of $5-8 \mathrm{~F}$ cells treated with $25,50,100$ and $200 \mu \mathrm{M}$ TVA were $10.8,18.9,49.3$ and $80.2 \%$, respectively $(P<0.05)$, and those of $\mathrm{CNE}-2$ cells were 7.9, 15.2, 45.3 and 70.5\%, respectively $(\mathrm{P}<0.05)$ (Fig. 1b). The cytotoxic effect of TVA was much greater in the 5 -8F NPC cells $(E C 50=81.5 \mu \mathrm{M})$ than in CNE-2 cells $(\mathrm{EC} 50=124 \mu \mathrm{M})$.

\section{TVA induces apoptosis in NPC cells in a dose-dependent manner}

To investigate whether apoptosis causes inhibition of cell growth, we analyzed apoptosis after TVA treatment by flow cytometry analysis of annexin V/PI-stained cells. We found that TVA significantly induced apoptosis in a dose-dependent manner. Incubation of $5-8 \mathrm{~F}$ cells with 25,50 or $100 \mu \mathrm{M}$ TVA for $24 \mathrm{~h}$ caused $7.67,12.9 \%$ or $35 \%$ increases in total apoptosis, respectively. Similarly, after incubation with 2550 or $100 \mu \mathrm{M}$ CNE-2, the percentage of apoptotic cells was increased by $12.9,15.1 \%$ or $22.3 \%$, respectively (Fig. 2a). Cleaved poly (ADP-ribose) polymerase (PARP) and cleaved caspase-3 are widely used to detect apoptosis in cells. Therefore, we assessed the protein levels of cleaved PARP and cleaved caspase- 3 in the presence or absence of TVA treatment. Immunoblot analysis revealed that TVA treatment significantly increased the levels of cleaved PARP and cleaved caspase-3 in a time-dependent manner (Fig. 2c).

\section{TVA induces apoptosis in NPC cells through Akt and bad inactivation}

The Bcl-2-associated death promoter (Bad) is a proapoptotic member of the Bcl-2 family that can form a heterodimer with the antiapoptotic proteins Bcl-2 and Bcl-XL and prevent them from inhibiting apoptosis [21]. We were thus interested in determining whether TVA could affect endogenous Bad activity. The role of Bad in promoting apoptosis is mainly involves phosphorylation of Ser-136 and Ser-112. Bad is rapidly dephosphorylated and transferred to the mitochondria to induce apoptosis in response to external stimuli. As shown in Fig. 3a and $\mathrm{b}$, TVA treatment induced a decrease in Bad phosphorylation on Ser-136 and Ser-112 in a concentrationdependent manner. Protein kinases such as Akt phosphorylate Bad at Ser136, thereby blocking Bad-induced apoptosis. We were further interested in determining whether the Akt pathway is involved in TVA-induced apoptosis. The expression levels of Akt in the TVA groups were not significantly different from those in the control group; however, the expression levels of p-Akt were significantly reduced in a dose-dependent manner compared to those in the control group, correlating closely with the findings regarding Bad Ser-136 phosphorylation. To confirm the role of Akt activation in apoptosis induction by TVA, we determined the effects of IGF-1, an activator of Akt. As shown in Fig. 3c, the combination of IGF-1 and TVA could neutralize the inhibitory effect of TVA alone. The above results indicate that the Akt/Bad pathway is involved in TVA-induced apoptosis.

\section{Synergistic inhibitory effect of combining TVA with S63845 in NPC cells}

Mcl-1 is an anti-apoptotic member of the Bcl-2 family that inhibits apoptosis in response to a number of cytotoxic stimuli [22]. Mcl-1 is widely expressed in normal human tissues and is abnormally highly expressed in 


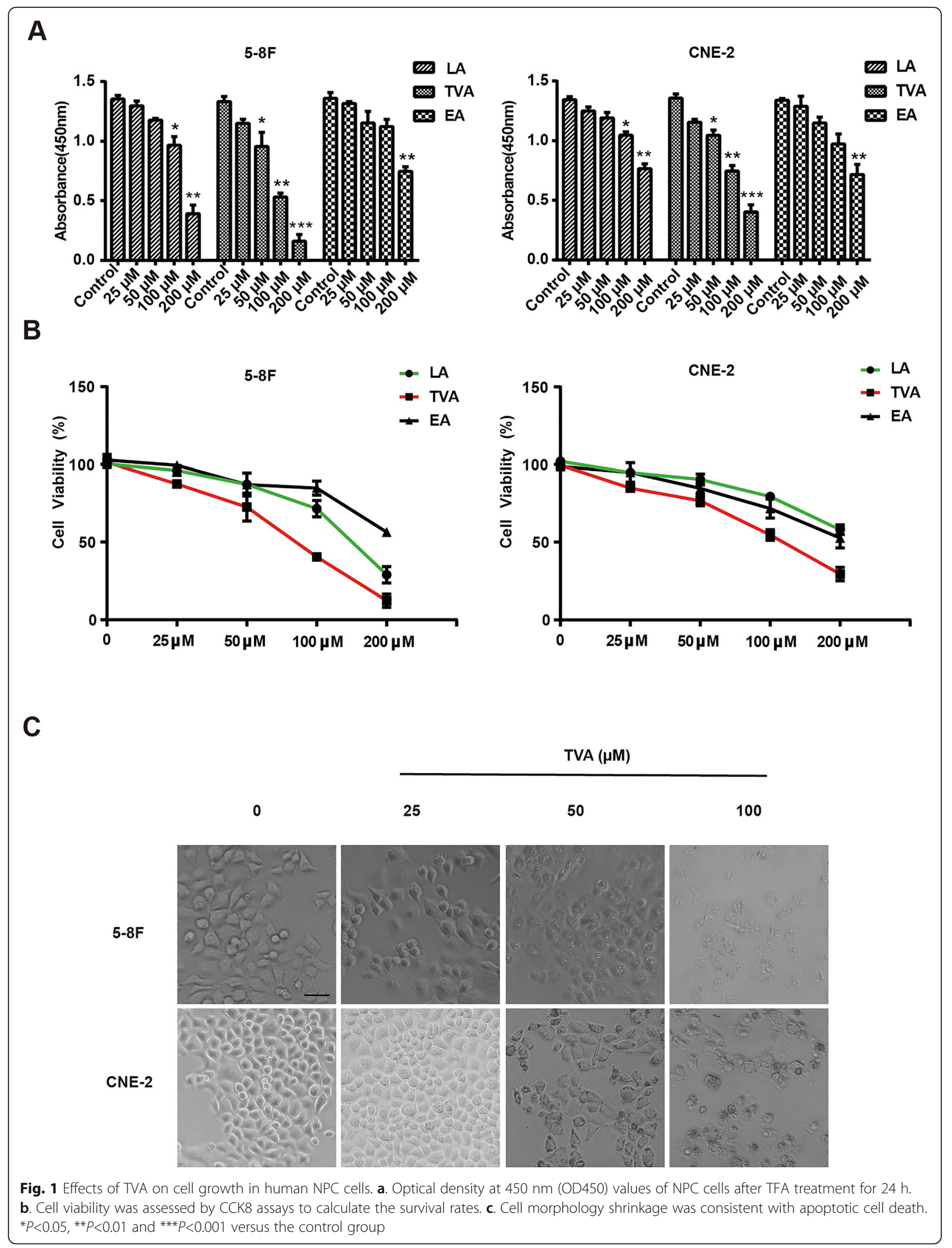




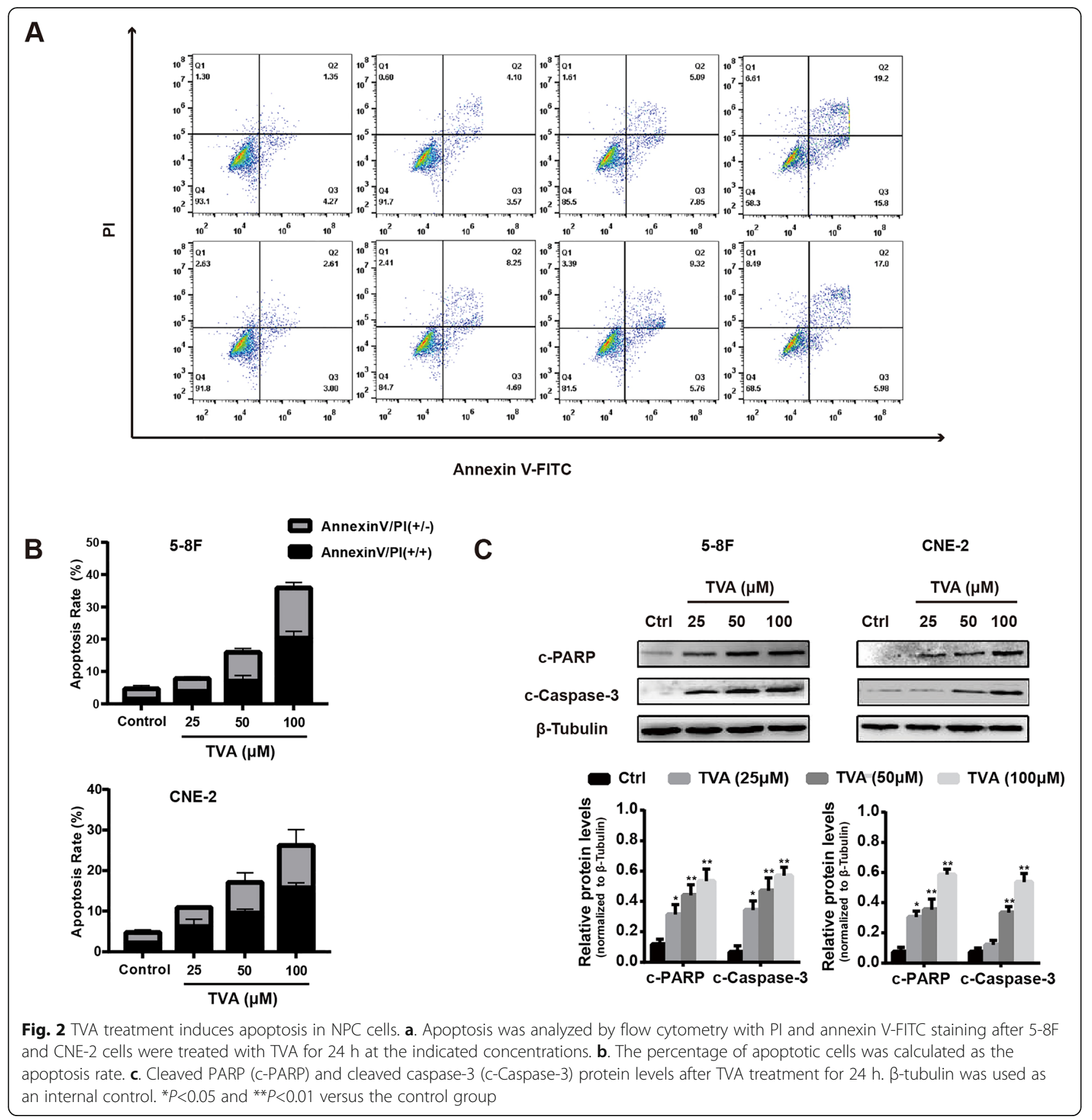

many malignant tumor tissues. As shown in Fig. 3a and b, TVA caused a significant increase in Mcl-1 expression in 5-8F and CNE-2 cells, which indicates that tumor cells are resistant to TVA. To verify our hypothesis, we treated cells with the Mcl-1 inhibitor S63845 combined with TVA and measured the overall inhibitory effects of the agents individually and in combination at a fixed ratio of 25:1 (TVA:S63845) using a CCK8 assay. As shown in Fig. 4a, S63845 treatment alone caused the inhibition of NPC cell growth, while the combination of TVA and S63845 was much more effectively than either alone. The CI value was less than 1 at all doses, suggesting that these two compounds have synergistic inhibitory effects on 5-8F and CNE-2 cells.

\section{Discussion}

TFAs from different sources have unique biological effects. Many clinical and experimental studies have shown that the consumption of TFA from partially hydrogenated oils not only adversely affects the cardiovascular system but also accelerates the occurrence of diseases such as obesity and tumors [23, 24]. However, 

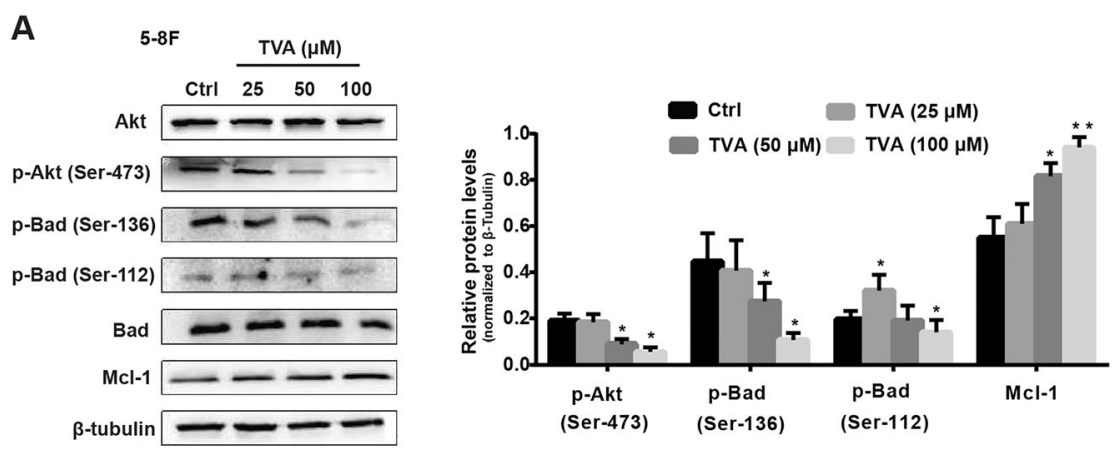

B
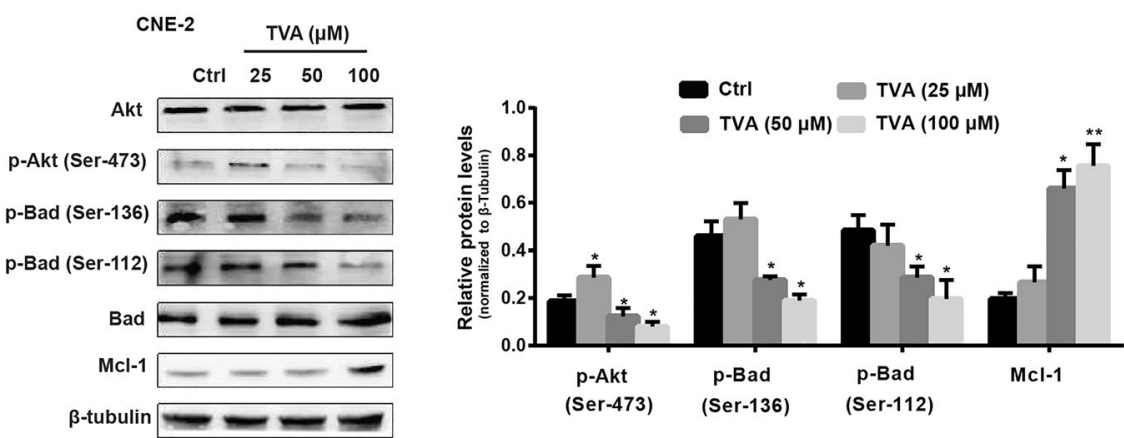

C

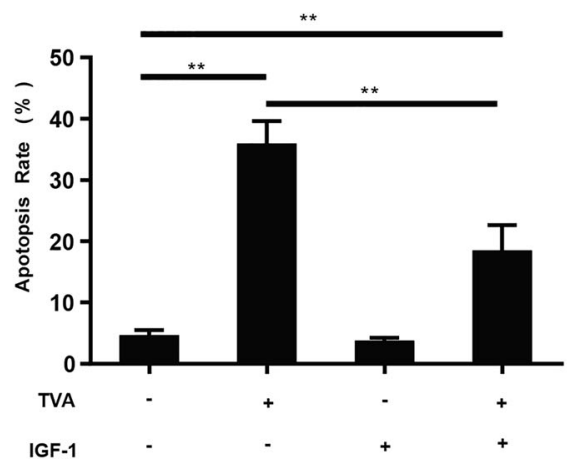

Fig. 3 TVA induces apoptosis in NPC cells through Akt and Bad inactivation. a. The expression of Akt, p-Akt, Bad, p-Bad and Mcl-1 in 5-8F cells was analyzed by western blot assay after the cells were treated with TVA. b. The expression of Akt, p-Akt, Bad, p-Bad and Mcl-1 in CNE-2 cells was analyzed by western blot assay after the cells were treated with TVA. Protein expression was quantified by normalization to the level of $\beta$-tubulin. c. Effects of IGF-1 on TVA-induced apoptosis as detected by an annexin V-FITC/PI staining assay. The number of apoptotic cells was determined after treatment with TVA $(100 \mu \mathrm{M})$ in the presence or absence of IGF-1 $(50 \mathrm{ng} / \mathrm{mL})$ for $24 \mathrm{~h}$. The values represent the means \pm standard deviation of three independent experiments. ${ }^{*} P<0.05$ and ${ }^{* *} P<0.01$ versus the control group

in recent years, increasing evidences has demonstrated that TFAs from ruminant trans fats have beneficial effects on human health [25]. In the present study, we examined the anticancer effects of TVA on human NPC 5-8F and CNE-2 cells and explored the related molecular mechanisms. Furthermore, we found that TVA treatment can promote a significant increase in Mcl-1 leading to drug resistance in NPC cells, which could be overcome by treatment with the Mcl-1 inhibitor S63845.
Apoptosis is an autonomous, ordered death of cells controlled by gene regulation. Biochemical events occur during this process, which is characterized by blebbing, cell shrinkage and nuclear fragmentation [26]. Apoptosis of cancer cells is an important mechanism to inhibit cell growth, and inducing tumor cell apoptosis has become the first choice for clinical anticancer therapy [27]. Therefore, we examined whether TVA could induce apoptosis in NPC cells in the present study. The CCK8, annexin V-FITC/PI staining, and western blot assay 
A
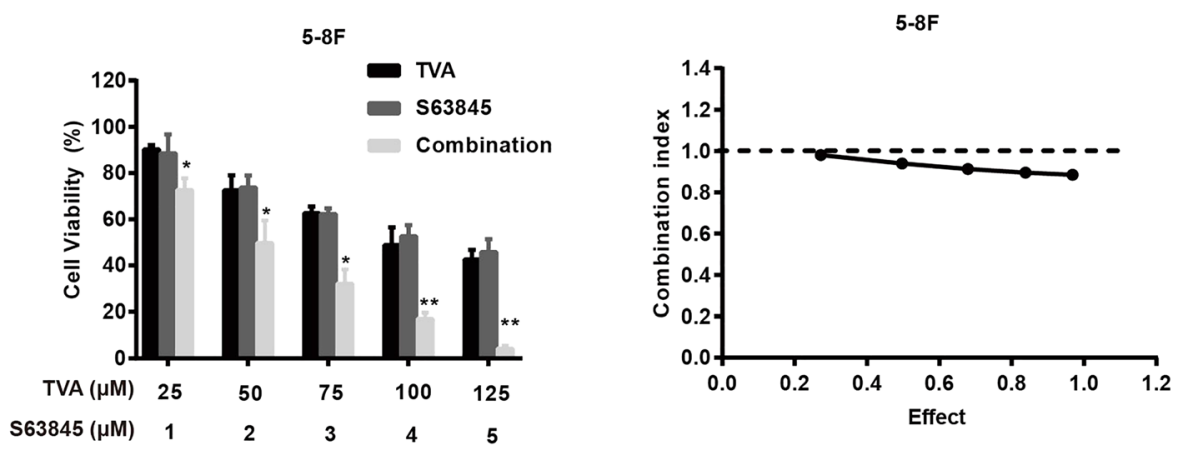

B

CNE-2

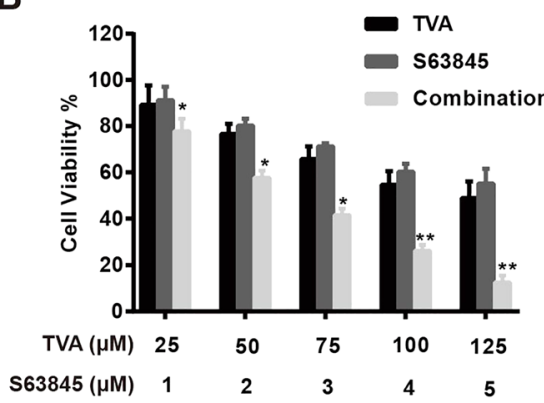

CNE-2

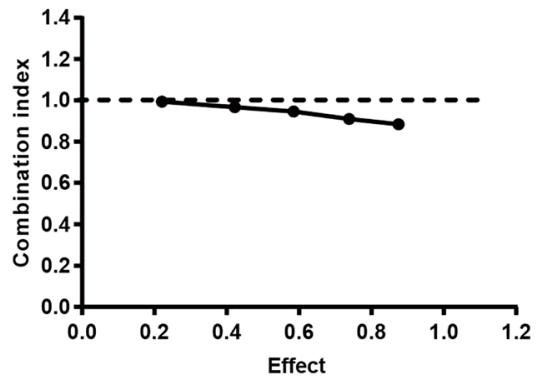

C

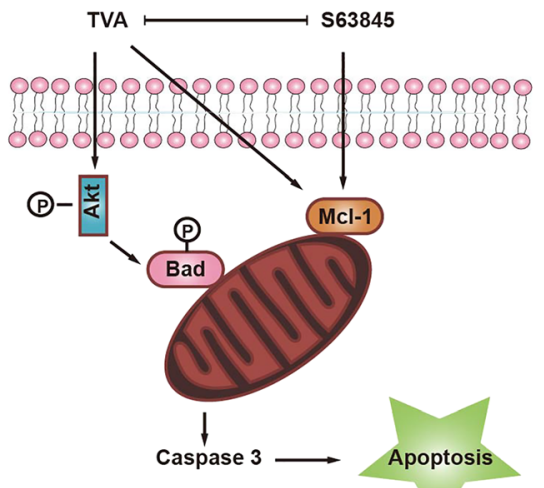

Fig. 4 Synergistic inhibitory effect of the combination of TVA and S63845 on NPC cells. a. Cell viability of NPC cells after treatment with TVA (25, 50, 75, 100 and $125 \mu \mathrm{M})$, S683845 $(1,2,3,4$ and $5 \mu \mathrm{M})$ or a combination of TVA and S63845 in a fixed ratio of 25:1 (TVA:S63845) for $24 \mathrm{~h}$. b. Cl value of the TVA/S63845 combination at each fixed ratio concentration. c. Signaling pathways underlying TVA and/or S63845-induced apoptosis in NPC cells

results revealed that the viability of $5-8 \mathrm{~F}$ and $\mathrm{CNE}-2$ cells was inhibited by TVA in the range of $25-100 \mu \mathrm{M}$ in a dose-dependent manner $(P<0.05)$.

Bad is a pro-apoptotic member of the Bcl-2 family. Remarkably, dephosphorylated Bad, but not phosphorylated Bad, forms a heterodimer with the antiapoptotic proteins $\mathrm{Bcl}-2$ and $\mathrm{Bcl}-\mathrm{XL}$, inactivating them and thus allowing apoptosis [28]. Phosphorylated Bad is located in the cytoplasm and has no pro-apoptotic activity [29].
Phosphorylation of Ser-112 and/or Ser-136 of Bad leads to the loss of proapoptotic activity [30]. Our results show that TVA can induce a concentration-dependent decrease in Bad phosphorylation at both Ser-136 and Ser-112. However, as a common protein in multiple signaling pathway, Bad is phosphorylated by several protein kinases such as those induced by survival signals. The Akt signaling pathway plays an important role in controlling tumor cell proliferation, the cell cycle and 
metastasis [31]. Furthermore, Akt, have been reported to phosphorylate Bad in response to survival signals [32]. IOur study, we found that the decrease in Bad phosphorylation was consistent with Akt-mediated dephosphorylation. Specific activation of Akt (by IGF-1) inhibited apoptosis and significantly attenuated the inhibitory effect of TVA. TVA promotes NPC apoptosis by targeting the Akt/Bad signaling pathway.

Tumor cells develop drug resistance for many reasons, among which apoptotic regulation of protein expression is an important factor [33]. In various types of tumor cells, anti-apoptotic genes of the Bcl-2 family are highly expressed, thereby preventing apoptosis [34]. Mcl-1 is a member of the antiapoptotic Bcl-2 family of proteins. Abundant evidence to suggests that Mcl-1 is an important cancer target [35]. The root cause of resistance to widely used anticancer drugs, including Bcl-2 inhibitors [36], paclitaxel [37], vincristine [37], and gemcitabine [38] is upregulation of the Mcl-1 level. In the present study, TVA treatment induced Mcl-1 expression. To inhibit drug resistance resulting from Mcl-1 upregulation, we used the newly developed Mcl-1 inhibitor S63845 combinated with TVA and showed that the two compounds have a synergistic effect. Therefore, targeting Mcl-1 is a rational strategy to improve the efficacy of TVA.

\section{Conclusions}

The present investigation confirms that TVA exerts a significant anti-NPC effect on 5-8F and CNE-2 cells in vitro. The anticancer activity of TVA can be attributed to its inhibition of proliferation and its induction of apoptosis through the inhibition of Bad/Akt phosphorylation. However, the increased expression of Mcl-1 will partly compromise the efficacy of TVA. Thus, the combined use of TVA and Mcl-1 inhibitors is a promising prospect for nasopharyngeal cancer treatment.

\section{Abbreviations}

Cl: Combination index; EA: Elaidic acid; HDL: High-density lipoprotein; LA: Linoelaidic acid; LDL: Low-density lipoprotein; NPC: Nasopharyngeal carcinoma; TFAs: Trans fatty acids; TVA: Trans-vaccenic acid

\section{Acknowledgements}

We thank all of the participants for their contribution to this study.

\section{Funding}

This work was supported by China Postdoctoral Foundation (2017 M622876), Development and Reform commission of Shenzhen Municipality (S2016005470013), Shenzhen Science and Technology Innovation Committee(JCYJ20170306091452714, JCYJ20170413162242627, GJHZ20170313172439851).

\section{Availability of data and materials}

Data and material were available.

\section{Authors' contributions}

JS, YW, GN designed the study; JS, YW, QF, WH, JH, MY, LL performed the experiment. JS and GN evaluated the literature; JS, GN undertook the statistical analysis and wrote the first draft of the manuscript. All authors have approved the final manuscript for publication.
Ethics approval and consent to participate

The study protocol was approved by the Ethics Committee of Shenzhen Second People's Hospital.

\section{Consent for publication}

All authors have approved the final manuscript for publication.

\section{Competing interests}

The authors declare that they have no competing interests.

\section{Publisher's Note}

Springer Nature remains neutral with regard to jurisdictional claims in published maps and institutional affiliations.

\section{Author details}

'Department of Otolaryngology, Shenzhen Second People's Hospital, The First Affiliated Hospital of Shenzhen University, Shenzhen 518035, People's Republic of China. ${ }^{2}$ Institute of Translational Medicine, Shenzhen Second People's Hospital, The First Affiliated Hospital of Shenzhen University, Shenzhen 518035, People's Republic of China. ${ }^{3}$ Department of Otolaryngology, Peking University Shenzhen Hospital, Shenzhen 518036, People's Republic of China. ${ }^{4}$ Department of Otolaryngology, Shenzhen People's Hospital, The second Affiliated Hospital of Jinan University,

Shenzhen 518000, People's Republic of China.

Received: 7 November 2018 Accepted: 4 February 2019

Published online: 09 February 2019

\section{References}

1. Lichtenstein $\mathrm{AH}$. Dietary trans fatty acids and cardiovascular disease risk: past and present. Curr Atheroscler Rep. 2014;16:433.

2. Gebauer SK, Psota TL, Kris-Etherton PM. The diversity of health effects of individual trans fatty acid isomers. Lipids. 2007;42:787-99.

3. Te Morenga L, Montez JM. Health effects of saturated and trans-fatty acid intake in children and adolescents: systematic review and meta-analysis. PLoS One. 2017;12:e0186672.

4. Dawczynski C, Lorkowski S. Trans-fatty acids and cardiovascular risk: does origin matter? Expert Rev Cardiovasc Ther. 2016;14:1001-5.

5. Brouwer IA, Wanders AJ, Katan MB. Effect of animal and industrial trans fatty acids on HDL and LDL cholesterol levels in humans--a quantitative review. PLoS One. 2010;5:e9434.

6. Ascherio A. Trans fatty acids and blood lipids. Atheroscler Suppl. 2006;7:25-7.

7. Han SN, Leka LS, Lichtenstein AH, Ausman LM, Schaefer EJ, Meydani SN. Effect of hydrogenated and saturated, relative to polyunsaturated, fat on immune and inflammatory responses of adults with moderate hypercholesterolemia. J Lipid Res. 2002;43:445-52.

8. Da Silva MS, Bilodeau JF, Larose J, Greffard K, Julien P, Barbier O, Rudkowska I. Modulation of the biomarkers of inflammation and oxidative stress by ruminant trans fatty acids and dairy proteins in vascular endothelial cells (HUVEC). Prostaglandins Leukot Essent Fatty Acids. 2017;126:64-71.

9. Sarabi M, Vessby B, Millgård J, Lind L. Endothelium-dependent vasodilation is related to the fatty acid composition of serum lipids in healthy subjects. Atherosclerosis. 2001;156:349-55.

10. Thom E, Wadstein J, Gudmundsen O. Conjugated linoleic acid reduces body fat in healthy exercising humans. J Int Med Res. 2001;29:392-6.

11. Salmerón J, Hu FB, Manson JE, Stampfer MJ, Colditz GA, Rimm EB, Willett WC. Dietary fat intake and risk of type 2 diabetes in women. Am J Clin Nutr. 2001;73:1019-26.

12. King IB, Kristal AR, Schaffer S, Thornquist M, Goodman GE. Serum $<$ em $>$ trans $</$ em $>$-fatty acids are associated with risk of prostate cancer in $\beta$-carotene and retinol efficacy trial. Cancer Epidemiol Biomarkers Prev. 2005;14:988-92

13. Wang $\mathrm{T}$, Lee $\mathrm{HG}$. Advances in research on cis-9, trans-11 conjugated linoleic acid: a major functional conjugated linoleic acid isomer. Crit Rev Food Sci Nutr. 2015;55:720-31.

14. Degen C, Lochner A, Keller S, Kuhnt K, Dänicke S, Jahreis G. Influence of in vitro supplementation with lipids from conventional and alpine milk on fatty acid distribution and cell growth of HT-29 cells. Lipids Health Dis. 2011;10:131.

15. Miller A, McGrath E, Stanton C, Devery R. Vaccenic acid (t11-18:1) is converted to c9,t11-CLA in MCF-7 and SW480 cancer cells. Lipids. 2003;38:623-32. 
16. Lin G, Zhu S, Wu Y, Song C, Wang W, Zhang Y, Chen Y-L, He Z. w-3 free fatty acids and all-trans retinoic acid synergistically induce growth inhibition of three subtypes of breast cancer cell lines. Sci Rep. 2017;7:2929.

17. Carioli G, Negri E. Global trends in nasopharyngeal cancer mortality since 1970 and predictions for 2020: Focus on low-risk areas. Int J Cancer. 2017; 140:2256-64.

18. Caponigro F, Longo F, lonna F, Perri F. Treatment approaches to nasopharyngeal carcinoma: a review. Anti-Cancer Drugs. 2010;21:471-7.

19. Zhang L, Huang $Y$, Hong $S$, Yang $Y, Y u$ G, Jia J, Peng P, Wu X, Lin Q, Xi X, et al. Gemcitabine plus cisplatin versus fluorouracil plus cisplatin in recurrent or metastatic nasopharyngeal carcinoma: a multicentre, randomised, open-label, phase 3 trial. Lancet. 2016;388:1883-92.

20. Chou TC, Talalay P. Quantitative analysis of dose-effect relationships: the combined effects of multiple drugs or enzyme inhibitors. Adv Enzym Regul. 1984:22:27-55.

21. Yan J, Xiang J, Lin Y, Ma J, Zhang J, Zhang H, Sun J, Danial Nika N, Liu J, Lin A. Inactivation of BAD by IKK Inhibits TNF\&\#x3b1;-Induced Apoptosis Independently of NF-\&\#x3ba;B Activation. Cell. 2013;152:304-15.

22. Zhou P, Qian L, Kozopas KM, Craig RW. MCl-1, a BCl-2 family member, delays the death of hematopoietic cells under a variety of apoptosis-inducing conditions. Blood. 1997:89:630-43.

23. Katan MB. Trans fatty acids and plasma lipoproteins. Nutr Rev. 2000;58:188-91.

24. Vincent MJ, Allen B, Palacios OM, Haber LT, Maki KC. Meta-regression analysis of the effects of dietary cholesterol intake on LDL and HDL cholesterol. Am J Clin Nutr. 2019;109(1):7-16.

25. Lim J-N, Oh J-J, Wang T, Lee J-S, Kim S-H, Kim Y-J. Lee H-G: trans-11 18:1 Vaccenic acid (TVA) has a direct anti-carcinogenic effect on MCF-7 human mammary adenocarcinoma cells. Nutrients. 2014;6:627.

26. Tixeira R, Caruso S, Paone S, Baxter AA, Atkin-Smith GK, Hulett MD, Poon $\mathrm{KKH}$. Defining the morphologic features and products of cell disassembly during apoptosis. Apoptosis. 2017;22:475-7.

27. Kelly PN, Strasser A. The role of $\mathrm{BCl}-2$ and its pro-survival relatives in tumourigenesis and cancer therapy. Cell Death Differ. 2011;18:1414.

28. Danial NN, Korsmeyer SJ. Cell death. Cell. 2004;116:205-19.

29. Datta SR, Ranger AM, Lin MZ, Sturgill JF, Ma Y-C, Cowan CW, Dikkes P, Korsmeyer SJ, Greenberg ME. Survival factor-mediated BAD phosphorylation raises the mitochondrial threshold for apoptosis. Dev Cell. 2002;3:631-43.

30. Zha J, Harada H, Yang E, Jockel J, Korsmeyer SJ. Serine phosphorylation of death agonist $B A D$ in response to survival factor results in binding to 14-3-3 not $B C L-X<$ sub $>L</$ sub $>$. Cell. 1996;87:619-28.

31. Zhang Y, Liu X, Zhang J, Li L, Liu C. The expression and clinical significance of PI3K, pAkt and VEGF in colon cancer. Oncol Lett. 2012;4:763-6.

32. She Q-B, Solit DB, Ye Q, O'Reilly KE, Lobo J, Rosen N. The BAD protein integrates survival signaling by EGFR/MAPK and PI3K/Akt kinase pathways in PTEN-deficient tumor cells. Cancer Cell. 2005;8:287-97.

33. Bhattacharya S, Ray Ramesh M, Johnson Leonard R. STAT3-mediated transcription of BCl-2, MCl-1 and c-IAP2 prevents apoptosis in polyaminedepleted cells. Biochem J. 2005:392:335-44.

34. Delbridge ARD, Grabow S, Strasser A, Vaux DL. Thirty years of BCL-2: translating cell death discoveries into novel cancer therapies. Nat Rev Cancer. 2016;16:99

35. Belmar J, Fesik SW. Small molecule Mcl-1 inhibitors for the treatment of cancer. Pharmacol Ther. 2015;145:76-84.

36. Wang Y, Wang Y, Fan X, Song J, Wu H, Han J, Lu L, Weng X, Nie G. ABT-199mediated inhibition of $\mathrm{BCl}-2$ as a potential therapeutic strategy for nasopharyngeal carcinoma. Biochem Biophys Res Commun. 2018;503:1214-20.

37. Wertz IE, Kusam S, Lam C, Okamoto T, Sandoval W, Anderson DJ, Helgason E, Ernst JA, Eby M, Liu J, et al. Sensitivity to antitubulin chemotherapeutics is regulated by MCL1 and FBW7. Nature. 2011;471:110.

38. Wei S-H, Dong K, Lin F, Wang X, Li B, Shen J-J, Zhang Q, Wang R, Zhang HZ. Inducing apoptosis and enhancing chemosensitivity to gemcitabine via RNA interference targeting Mcl-1 gene in pancreatic carcinoma cell. Cancer Chemother Pharmacol. 2008;62:1055-64.

Ready to submit your research? Choose BMC and benefit from:

- fast, convenient online submission

- thorough peer review by experienced researchers in your field

- rapid publication on acceptance

- support for research data, including large and complex data types

- gold Open Access which fosters wider collaboration and increased citations

- maximum visibility for your research: over $100 \mathrm{M}$ website views per year

At BMC, research is always in progress.

Learn more biomedcentral.com/submissions 